\title{
Representar al subalterno: análisis del discurso silenciado de Mariama Bâ y de Rosalía de Castro en dos contextos similares de dominación falocrática
}

\author{
Representing the Subaltern: Analysis of the Silenced Discourse \\ of Mariama Bâ and Rosalía de Castro in Two Similar Contexts \\ of Phallocratic Domination
}

\author{
María Obdulia Luis Gamallo \\ Universidad de A Coruña, España
}

Resumen: Este trabajo se centra en las repercusiones sociales y literarias del discurso silenciado de dos mujeres, Rosalía de Castro, escritora emblemática del Rexurdimento literario gallego en el siglo XIX, y Mariama Bâ, una de las pioneras de la literatura femenina africana de expresión francesa, que cuestiona la poligamia en la sociedad senegalesa postcolonial. Ambas escritoras luchan en un contexto falocrático destinado a silenciar al grupo social autóctono, y en particular a las mujeres, doblemente colonizadas, esclavas domésticas y siervas de la colonización, encargadas de transmitir el discurso dominante en el núcleo familiar. Desde un punto de vista comparativo y dentro de los estudios postcoloniales, abordaremos la marginalización a la que son sometidas las otras por su doble condición de mujeres y subalternas.

Palabras clave: postcolonialismo, feminismo, subalternidad, Rosalía de Castro, Mariama Bâ, Mi carta más larga.

Abstract: This work focuses on the social and literary repercussions of the silent discourse of two women, Rosalía de Castro, emblematic writer of the Galician literary Renaissance in the $19^{\text {th }}$ century, and Mariama Bâ, one of the pioneers of African women's literature. French-speaking, questioning polygamy in postcolonial Senegalese society. The two writers fight in a phallocratic context intended to ignore the indigenous social group and in particular the women, doubly colonized, domestic slaves serving colonization, responsible for transmitting the dominant discourse within families. From a comparative point of view and within postcolonial studies, we will deal with the marginalization to which others are subjected due to their dual status as women and subordinates.

Keywords: postcolonialism, feminism, subalternity, Rosalía de Castro, Mariama Bâ, Such a long letter. 
I. Este trabajo procura analizar las repercusiones sociales y literarias del discurso silenciado de dos mujeres, Rosalía de Castro y Mariama Bâ, la primera en la Galicia del siglo XIX en pleno proceso de recuperación cultural y lingüística, la segunda en el Senegal postcolonial de mediados del siglo XX con la independencia política y cultural francesa como telón de fondo. Ambas mujeres luchan en un contexto falocrático similar, dominado por una presencia extranjera que impone un sistema ideológico, económico y político, destinado a silenciar al grupo social autóctono y particularmente a las mujeres. Estas, doblemente colonizadas, esclavas domésticas y siervas de la colonización, son las encargadas de transmitir el discurso dominante en el núcleo familiar.

En un primer momento, haremos referencia a Mariama Bâ, a sus orígenes sociales y culturales, a su combate y a su obra literaria, centrándonos particularmente en su primera novela, Une si longue lettre. En un segundo momento, presentaremos el combate de Rosalía, su lucha contra toda una serie de prejuicios genéricos, sociales, políticos y lingüísticos destinados a silenciar su voz y a denigrar su función social y literaria. Por último, destacaremos las similitudes y diferencias en el discurso de ambas escritoras y las repercusiones en cada uno de los campos sociales y literarios en el que publican las dos autoras.

II. Mariama Bâ (1929-1981) es una de las voces femeninas más significativas del África postcolonial de expresión francesa. Logró imponerse en el panorama literario de su país de dominación casi exclusivamente masculina. Al fallecer su madre, sus abuelos se ocupan de su educación en una escuela coránica. Como mujer de condición musulmana, Mariama estaba destinada a realizar únicamente estudios primarios, pero gracias a su padre, médico y futuro Ministro de Salud de Senegal, y a dos mujeres, Berthe Maubert, maestra en la escuela colonial, y Germaine Le Goff, directora de la primera Escuela femenina de Magisterio del África Occidental Francesa, Mariama pudo continuar su formación académica. El padre, de talante progresista y liberal, indiferente a las tradiciones, le inculcó el gusto por la lectura y la matriculó en la escuela colonial francesa. Berthe Maubert, consciente de las actitudes literarias de la niña y del esplendor que una alumna brillante podría aportar a su centro y por extensión a la escuela colonial, le dio clases de lengua y de gramática francesas fuera de las horas reglamentarias. En lo que se refiere a Germaine Le Goff, la directora de la Escuela de Magisterio, su intervención fue determinante para que los abuelos de Mariama aceptaran que la entonces adolescente cursara estudios superiores. Mariama se licenció en 1947 y durante doce años se dedicó a la enseñanza hasta que, por motivos de salud, tuvo que integrar la Inspección Regional de Enseñanza. Desde un militantismo asociativo destinado a luchar contra las castas y la poligamia, Mariama, madre de nueve hijos, reclamará a lo largo de su vida la misma educación para niños y niñas, defendiendo sobre todo los derechos de las mujeres. La mujer musulmana educada en el sistema colonial se mantendrá a lo largo de su vida apegada a la religión y a las tradiciones, rechazando cualquier forma de asimilación: "On a blanchi ma raison et ma tête est restée noire. Mais mon sang inattaquable piaffe dans mes veines civilisées" (Dia, 1979). La influencia de la abuela materna, de origen noble, respetuosa de los valores ancestrales y contraria a la influencia colonial francesa, fue determinante en el apego de Mariama a la tradición. La vida de la escritora va a ser una lucha constante 
y contradictoria entre tradición y modernidad. Enferma, fallece dos años después de la publicación de Une si longue lettre (1979), traducida a diecisiete idiomas, y justo antes de publicar Le Chant écarlate (1981). Es también autora de La fonction politique des littératures africaines écrites (1981).

Mariama Bâ forma parte de ese grupo de feministas africanas que piensan la mujer en su universo personal, en la relación consigo mismas, en un combate político e intelectual propio. Hasta los años cincuenta, la literatura negra es dominio reservado a una élite masculina y las primeras novelas africanas escritas por mujeres nacen como un juego de voces narrativas polifónicas, un "yo" que se define en relación al hombre en la esfera pública y privada, en una sociedad dirigida y controlada por hombres. La revuelta femenina surge cuando la mujer decide romper con la realidad supuestamente protectora y conciliadora del sistema falocrático vigente, y se rebela contra la sumisión a unas normas sociales que reducen a la mujer a un objeto de comercio. Ahora bien, al mismo tiempo que la mujer defiende la evolución de las mentalidades, se posiciona en un discurso indulgente con las tradiciones y la herencia cultural africana. Este movimiento cultural, en el que se inscriben las obras de Mariama Bâ, fue inaugurado por las novelistas africanas anglófonas y se trasladó posteriormente al espacio africano francófono (Ondo, 2009). El "Womanism", término acuñado por la escritora afroamericana Alice Walker en I Search of Our Mothers'Gardens, A Womanist Prose (1983), estima que la mujer tiene que evolucionar en el interior de la esfera cultural que le es propia y que constituye su fuerza, para integrarse profesionalmente en la sociedad. El "womanism" no reivindica la justicia, se apropia de ella sin ultrajar al hombre ni asumir la segregación sexual, siendo la escritura el medio más eficaz para cambiar el orden social impuesto desde los intereses masculinos. En 1985, la nigeriana Chikwenye Okonjo Ogunyemi llega a las mismas conclusiones que Alice Walter, aunque de forma independiente. Hoy se habla de "African Womanism", movimiento que tiene en cuenta las peculiaridades propias de la mujer africana para denunciar la extrema pobreza en la que vive, los problemas con las familias políticas, la opresión que las mujeres de mayor edad ejercen sobre las más jóvenes, la opresión que sufren las coesposas y finalmente la cuestión de los fundamentalismos religiosos, islámicos o cristianos, y de las religiones tradicionales. El "African Womanism" concede especial atención a la maternidad, principio estabilizador por excelencia, esencial para la mujer africana, y rechaza el lesbianismo defendido por el "Womanism" (Pérez Ruiz, 2015, pp. 17-18).

En Une si longue lettre, Ramatoulaye, recluida en su casa durante los cuarenta días que dura el luto por el esposo fallecido, responde a la carta que le dirige su amiga Aïssatou y la confidencia se convierte en catarsis del dolor. Se privilegia el género epistolar para evocar la vida íntima del personaje, género cuyos antecedentes remontan al siglo XIX, a la cultura islámica, en concreto al "mirasse", dictado por el Corán. En éste se exigía que el difunto fuese despojado de sus secretos más íntimos exponiéndolos a otras personas (Pérez Ruiz, 2015, p. 40). Ramatatoulaye, que acaba de enviudar, revela a su amiga Aïssatou detalles de la vida del esposo fallecido que nunca antes había desvelado. Con una voz de mujer en primera persona que se confunde en no pocas ocasiones con la voz de la autora, Ramatoulaye evoca la amistad de las dos mujeres que data de la época de sus abuelas; ambas siguen el mismo recorrido escolar, se casan con dos intelectuales que escogen libremente por amor y las dos son víctimas de la poligamia, situación que las separa geográfica e 
ideológicamente. Aïssatou se divorcia y emigra por dignidad para huir de una moral y de unas leyes que someten a las mujeres africanas. Se instala con sus hijos en Estados Unidos en donde trabajará para la embajada de Senegal. Allí conseguirá huir de la opresión de la estructura familiar tradicional y dejar atrás la alienación y la domesticación que sufren las niñas desde siglos atrás. Ramatoulaye piensa que los hijos no pueden crecer lejos del padre en la medida en que la familia es el principio unificador de toda nación. Decide quedarse con el padre de sus doce hijos a pesar de la vejación de haber sido abandonada por una compañera de estudios de su hija adolescente. Su inmovilismo comienza a cambiar cuando Aïssatou le regala un coche que le permite desplazarse sin hacer uso de los transportes públicos, prueba de una relativa mejora social. El feminismo de interior, su pasividad, el lugar subordinado que ocupa como la otra en el espacio clausurado del hogar, comienza a acercarse a la masculinidad, a la acción de Aïssatou, prueba de la transformación de la protagonista. Ramatoulaye describe la poligamia como humillante y le cuesta concebir la felicidad en la soledad, pero rechaza el matrimonio que le proponen, primero, su cuñado Tamsir, poco después, su novio de juventud, Daouda Dieng, que ya tiene una esposa a la que ella infringiría el tormento de la poligamia. Ramatoulaye muestra una gran dignidad, rechaza las facilidades materiales que le aportaría un segundo matrimonio, pues considera que la mujer no debe ser objeto de comercio alguno. Esta actitud se inscribe en un movimiento de solidaridad entre mujeres, próximo al feminismo, conocido internacionalmente como feminitud, que se distancia del primero porque no defiende la igualdad entre el hombre y la mujer, sino la diferencia igualitaria entre ambos sexos, insistiendo en las características específicas de la mujer.

El relato de Ramatoulaye nos conduce de lleno al corazón de la intimidad de la mujer africana, al desgarro interior que la divide entre sus obligaciones de mujer educada en la tradición musulmana y el espíritu libre inculcado en las escuelas coloniales, al deseo de afirmarse sin tener necesidad de rivalizar con el hombre o de precisar su reconocimiento. No se condena el trabajo doméstico de la mujer que se siente realizada en su ejecución diaria, consciente de que la base del funcionamiento de una sociedad y de un país está en la familia y ésta depende de la mujer: "Ce sont toutes les familles, riches ou pauvres, unies ou déchirées, conscientes ou irréfléchies qui constituent la Nation. La réussite d'une nation passe donc irrémédiablement par la famille" (Bâ, 1979, p. 164). Se trata de un feminismo de raigambre africana que responde a las necesidades de las mujeres del continente, un feminismo que se impone en la sociedad de los años setenta, basado en la solidaridad entre mujeres, en absoluto comparable al feminismo de corte occidental que defiende la igualdad entre el hombre y la mujer, concibe la mujer como un ser individual y critica los roles tradicionales femeninos.

La amistad que unió a las alumnas de la Escuela de mujeres de la que forman parte Ramatoulaye y Aïssatou, va más allá del tiempo que duró su escolaridad. Estas mujeres, orgullosas de todo lo que constituye su feminidad, destacan por su incapacidad para ejercer el mal y por cualidades que tradicionalmente se le atribuyen a la mujer: paciencia, dulzura, compasión, comprensión, justicia. Esta feminidad las opone a las mujeres de generaciones anteriores, como la madre de Binetou (la co-esposa de Ramatoulaye) o la suegra de Aïssatou, que manipulan a todos los que las rodean sin ningún límite moral o ético. Aïssatou y Ramatoulaye son 
dos mujeres solidarias que trabajan de manera diferente para que la mujer se adapte poco a poco a la modernidad. Frente a la poligamia, reaccionan de manera distinta. Aïssatou se divorcia mientras que Ramatoulaye se queda con su esposo porque cree en el matrimonio como institución y en la complementariedad entre el hombre y la mujer. Todo en la novela nos conduce a la afirmación de los valores femeninos, sin hacer alusión a la supremacía masculina o al conflicto genérico. Empero, al feminismo de la escritora le falta radicalismo, debido al peso de la tradición musulmana y al largo período de silencio al que fue sometido el discurso femenino africano. En la África postcolonial de los años setenta, la mujer carece de visibilidad fuera del contexto familiar y los hombres dominan todo el espacio económico, político y social de la vida pública. Mariama Bâ ataca los factores más importantes de la alienación femenina, las tradiciones feudales, pero se instala en un discurso ambiguo, condicionada por los valores occidentales inculcados en la escuela colonial y renegando al mismo tiempo de la influencia extranjera.

Rosalía de Castro (1837-1885), figura emblemática del resurgir cultural y político de la Galicia de finales del siglo XIX, reducida a ser la voz popular y sentimental de los gallegos, es el centro de interés de multitud de estudios que recientemente procuran rehabilitar otra Rosalía, lejos de la imagen que se impuso de la escritora a lo largo del siglo XX, como mujer ajena al mundo intelectual, madre de familia numerosa afincada en provincias, sin identidad propia y subordinada a los intereses de su marido. Estudios recientes muestran a una Rosalía culta, con un elevado conocimiento de la literatura europea en su lengua originaria o en la traducción francesa correspondiente (como en la introducción a La hija del mar); una Rosalía que parodia un romanticismo creado y regido por principios masculinos, profundamente anticlerical y alejada de la moral religiosa que ciertos estudiosos consideran el principio unificador de su obra. El predominio y la utilización que hicieron Murguía y los autores del Rexurdimento de la poesía más popular de la autora es sin duda el origen de la desustancialización que sufrió su obra y su persona, relegándola a desempeñar un papel secundario en el Romanticismo español como autora carente de ideas, apartada de los círculos literarios e intelectuales de la época. En calidad de mujer y escritora, luchó por ser reconocida por el mérito de su creación artística, más allá del populismo y del sentimentalismo a los que la confinó la crítica hasta estudios relativamente recientes.

Su condición de hija ilegítima, la marginalizan desde dos estamentos sociales, la Iglesia y la aristocracia decadente. Su niñez en una aldea gallega junto a las tías paternas, la incomprensión de la que fue objeto por sus obras y sus ideas, la dificultad para conciliar escritura y feminismo, los años finales de su matrimonio con Murguía, sola y enferma en Padrón, hicieron de Rosalía, una mujer predestinada al dolor y al sufrimiento. Y son precisamente estos dos condicionantes, alejados de cualquier visión judeo-cristiana, los que le aportaron la lucidez necesaria para acceder a lo real dentro de las limitaciones literarias y existenciales que la acompañaron en vida. El dolor y el sufrimiento sometieron su fuero interior a una tiranía constante y le aportaron la lucidez, la desesperación y la humildad que condicionaron su vida y su obra. Dolor y sufrimiento hicieron la grandeza de Rosalía y dotaron a la artista de una especial sensibilidad para acceder a lo real y a los entresijos del alma humana.

La desesperación es el primer paso para liberarse del idealismo y del espiritualismo que dificultan el acceso del ser humano al mundo real. La desesperación genera 
sufrimientos, conflictos y catástrofes personales y libera la dosis de idealismo que acompaña a todo individuo, que lo exime a su vez del peso de las religiones alienantes que mantienen la esperanza boba en la mistificación de una vida mejor que compensaría y consolaría de los sufrimientos de ésta y que resulta ser el medio más legítimo que poseen los opresores de toda condición para mantener la dominación y la explotación de todos aquéllos que se resignan ante la miseria. Los poemas de Rosalía no incitan a la revuelta, pero son un grito descarnado contra la posición y la pobreza de los explotados, sean los trabajadores gallegos humillados en Castilla, sean las mujeres que, en la soledad y en la miseria de su situación, no encuentran descanso hasta la muerte. Rosalía mantuvo a lo largo de su vida una actitud ambivalente ante la religión y las creencias tradicionales, una desconfianza absoluta en el amor como sentimiento positivo y la certeza de que toda mujer, sea de la condición que sea, siempre será una víctima. Desesperación y lucidez anulan toda posibilidad de mistificación o de consolación en otra vida mejor. Desde este punto de vista, es difícil conciliar la idea de una moral cristiana como centro unificador de su obra, más bien sería preciso considerar la influencia de una ideología que, sin llegar a ser la del pensamiento libertario, laico y marxista de los pensadores franceses del Siglo de las Luces, posee la lucidez necesaria para abrir el camino a lo que serán los grandes movimientos obreros anarquistas y de liberalización de la mujer del siglo XX.

En el caso de Mariama, su actitud ante la tradición es ambivalente. Si bien se opone a determinados preceptos de la religión musulmana, como la poligamia o a la educación de las niñas, no logra desalienarse ni romper con el peso de una religión que aniquila la voluntad, genera y afirma como único posible, un mundo regido por el pensamiento y los intereses masculinos. Según Lilyan Kesteloot, la poligamia es hoy en día una estructura arcaica que tenía su razón de ser en sociedades en las que la mortalidad infantil era elevada y la supervivencia de la especie estaba en peligro. El hecho de que perdure en lo estados modernos, a pesar de la modificación sensible de las prácticas sanitarias y de la consiguiente explosión demográfica, sólo puede deberse a la voluntad masculina por conservar unos privilegios y beneficios contra los deseos o la voluntad del sexo opuesto. La poligamia instala a la mujer en un ciclo infernal de rivalidad con la/s esposa/s, no sólo para obtener una mayor atención del marido y beneficios para los hijos, sino también porque se trata de ver quien obtiene más favores del padre, provocando un combate en el interior del hogar. La mujer cae en un proceso repetitivo y degradante que le impide evolucionar (Kesteloot, 2009: 407-408). Por otra parte, es preciso subrayar el hecho de que fue precisamente de la mano del colonialismo, del cristianismo y del islam cuando la mujer comenzó a ser percibida, en el continente africano, como un ser negativo al que era preciso dominar por su carácter tentador y destructor. En el imaginario africano se venera a la mujer como madre de todas las cosas, por ser portadora de justicia, riqueza, sabiduría e hijos. No resulta anodino que las sociedades africanas adoren diosas femeninas, la tierra madre o el agua. Tradicionalmente, la mujer y el hombre eran seres complementarios: a la primera le correspondía todo lo relativo a la cosmología y a la metafísica; al segundo, la organización socio-política (Pérez Ruiz, 2008, p. 6). La situación no era muy diferente en la Galicia tradicional en la que se veneraba igualmente a la mujer como la Madre-Tierra, en honor a su fecundidad, y a la que se respetaba por su capacidad de decisión y por su fortaleza física. Del mismo modo que en el contexto africano, en Galicia la religión es portadora de un pensamiento 
antifeminista y falocrático y de una visión exógena y negativa de la mujer, ajena al imaginario gallego. En el siglo XIX, en Europa, se consideraba a la mujer como el sexo débil, menos inteligente que el hombre $y$, por ende, se la relegaba a la vida doméstica. En este aspecto como en otros muchos, Rosalía fue una precursora, puesto que muchos de los prejuicios sexistas denunciados un siglo más tarde por Virginia Woolf en A room of one's own (1929), están presentes en "Las literatas. Carta a Eduarda", sin olvidar el prólogo a La Hija del mar y "Lieders", verdaderos alegatos feministas avant la lettre. La visión negativa de la mujer que prevalece en Europa, se la llevarán a África los hombres enviados al continente a comienzos del siglo XIX, desinteresados por todo lo relativo al continente africano e impregnados de las teorías evolucionistas de la época que defendían la existencia de razas "atrasadas", menos evolucionadas que la civilización europea. Su rechazo era total cuando se trataba de las otras negras, lo más despreciable para el colonizador blanco en su escala de valores. Les llamaba la atención, al mismo tiempo que era motivo de rechazo, la resistencia física de estas mujeres y su capacidad para realizar los trabajos más duros (Pérez Ruiz, 2008, p. 7). De nuevo en esta caracterización se encuentra una clara similitud con la realidad de las mujeres gallegas, trabajando como hombres en el campo con una fuerza física descomunal que asombró a más de un viajero extranjero.

La historia de Galicia como la historia del África colonial y de sus mujeres está cargada de dolor y de sufrimiento. Y el sufrimiento es la base de la desesperación que proporciona una fuerza interior a seres excepcionales, dotados de una sensibilidad especial frente a la injusticia social. Ante la incapacidad de llenar el vacío existencial, origen del caos, con ilusiones como el amor o la religión, el escritor se instala en un pesimismo y un mal de vivre que lo conducen al rechazo de sí mismo. La vida de Mariama, como la de Ramatoulaye, está regida por la tradición y al mismo tiempo por la nostalgia de un tiempo consagrado a la abertura al mundo propugnado desde la escuela colonial. Ramatoulaye habla con mucha nostalgia de la directora de la Escuela Francesa, "la femme blanche qui, la première, a voulu pour nous un destin hors du commun" (Bâ, 1981, p. 37), de sus compañeras de promoción, de la riqueza intelectual, del conocimiento de otras culturas y de otras civilizaciones. Ramatoulaye transgrede la tradición cuando se casa por amor, a pesar de la oposición de sus padres. Se refiere luego a la felicidad que le aportó el matrimonio, al nacimiento de sus hijos y de cómo ese armonioso mundo desaparece cuando el esposo, sin previo aviso (como era de rigor en estos casos), decide casarse con Binetou y abandonar el hogar familiar. A partir de ese instante, Ramatoulaye pierde su identidad y entra en el círculo infernal de la poligamia, en una rivalidad estéril con la coesposa que genera destrucción y que aliena la mujer a los intereses del marido. La muerte del esposo conduce a Ramatoulaye a liberarse de un matrimonio convertido en suplicio y le aporta la posibilidad del cambio hacia otras propuestas sociales menos opresivas. Acepta el embarazo de su hija mayor y deja que acabe sus estudios, da consejos sobre sexualidad a sus hijas menores y se niega a ser un objeto mercantil para los dos hombres que la pretenden durante los cuarenta días que dura el luto y la reclusión en el hogar familiar:

Le monde est à l'envers. Les mères de jadis enseignaient la chasteté. Leur voix autorisée stigmatisait toute "errance" extra-conjugale. Les mères modernes favorisent les "jeux interdits". Elles aident à la limitation de leurs dégâts, mieux, à leur prévention. Elles ôtent toutes épines, tous cailloux qui 
gênent la marche de leurs enfants à la conquête de toutes les libertés! Je me plie douloureusement à cette exigence (Bâ, 1981, p. 161).

Rosalía rechaza su situación como mujer, esposa y madre, escritora e intelectual, ante la dificultad de conciliar ambas facetas de su vida, en una sociedad que acepta mal a la mujer fuera de su papel tradicional de madre y esposa y ante las dudas que le ocasiona el alcance real de su obra (pensemos en todo lo que mandó quemar a sus hijos antes de morir o del silencio en el que se sumió tras las críticas que siguieron a la publicación de los Cantares). Para Rosalía, únicamente es posible concebir el amor como ausencia, dolor y aniquilación de la ilusión femenina. Las creencias tradicionales, sus sombras, se vuelven más palpables y reales que el venturoso paraíso del catolicismo burgués dominante, orientado a la explotación de los más débiles, entre los que se encuentra, por supuesto, la mujer. Esta especial sensibilidad frente a la injusticia, fruto de una larga experiencia de dolor y de sufrimiento, se explica por la condición de su nacimiento, por la exclusión social y la educación culpabilizante y alienante, legitimada por la escuela y la Iglesia. La felicidad es inaccesible para una niña inteligente educada sin respuestas a la ausencia de sus padres. Cuando su madre retoma el rumbo de su educación en Santiago, la lectura, el contacto con los intelectuales europeos, la poesía, le rinden la posibilidad de liberar el dolor y muchos de los prejuicios religiosos y sexistas inculcados durante años.

Sin embargo, Rosalía no es una libertaria, asume su papel de madre y de esposa en el dolor y en lo que parece ser el abandono de Murguía durante su enfermedad. Su alma desposeída de todo, incluso de sí misma, lucha por no permanecer en el mundo de las sombras, pero al final de su vida, ella misma se vuelve sombra. La desesperación conlleva el rechazo del ideal claro e inteligible del mundo, de la belleza eterna y absoluta de inspiración divina, del amor de inspiración romántica. Llega incluso a negar la esperanza de los oprimidos. En razón de su condición de mujer, su intervención en el campo político y social de la época, exclusivamente falocráticos, está vetada, su compromiso va a ser sobre todo ético. La escritura es para Rosalía terapia. Dotada de una especial sensibilidad hacia las personas y las cosas, Rosalía siente, ve, comprende, lo que no resulta accesible a la mayoría de los mortales, condenando su sufrimiento a la incomprensión y burla de sus contemporáneos. La escritura le procura consolación estética ante las miserias de la vida cotidiana, las palabras como remediación a las sombras de la existencia. La poesía rosaliana traduce en palabras una experiencia dolorosa. Ante la desesperación, su alma aparece desnuda en unha entrega total de sí misma, de ahí que su poesía resulte más elocuente que la narrativa.

Siguiendo a Baudelaire, el arte puro conlleva la creación de una obra que contiene el objeto, el sujeto, el mundo exterior al artista y al propio artista. Desde esta perspectiva, el realismo es una falacia porque la obra de arte es la expresión de una experiencia única y personal, subjectiva, que depende de nuestra propia visión del mundo y de la realidad que reside en el interior de nosotros mismos. El escritor no es el sabio que intenta descubrir y explicar los misterios más recónditos de la naturaleza: la natureza es compleja y el lenguaje, insuficiente. La poesía de Rosalía no es un tratado sociológico, sino la descripción de una realidad, resultado de la experiencia y del fuero interior de una mujer atormentada, llena de dolor, una intelectual que no encuentra su lugar en un mundo regentado por principios y valores masculinos, 
madre de seis hijos, rechazada por su marido, enferma, creadora de una obra mal estudiada, parcialmente reconocida por la crítica y quizás en parte destruida al final de su vida y que sufrió en carne propia las consecuencias de la inestabilidad económica y geográfica de la familia Murguía de Castro.

Une si longue lettre es una obra subjetiva, narrada en primera persona, lo que la aleja de entrada del universo ordenado y convencional de la ideología burguesa. Las similitudes entre la vida de la protagonista, Ramatoulaye, y Mariama Bâ conducen al lector a una asimilación automática entre autor y obra, siendo la segunda una prolongación casi natural de la primera. Mariama aporta a su personaje una línea de conducta que le es proprio y deja al final de la obra una vía abierta a la liberalización de su protagonista. Sabemos que Mariama rechazó la poligamia, se divorció y se casó de nuevo. Ramatoulaye, sin embargo, se resigna ante su situación y parece escoger el inmovilismo y el espacio cerrado del hogar. Gracias a la redacción de la carta, toma conciencia de lo que fue su vida, su matrimonio, el dolor y la humillación frente al abandono, su papel de mujer exenta de voz y de decisión, confinada a las decisiones del mundo masculino en la estricta sociedad senegalesa.

En Le Deuxième Sexe (1949), Simone de Beauvoir, piensa que una vez casada, la mujer se convierte en el otro, la negación del hombre, y adquiere un papel pasivo en el núcleo familiar y en la esfera social. No se nace mujer, afirma la intelectual francesa, la mujer se hace a partir de la educación social y psicológica que genera las diferencias que hacen que la mujer se convierta en la negación del hombre. Rosalía fue pionera en su lucha por el reconocimiento de la mujer artista, en su dimensión estética, y por los efectos de sus intervenciones en el campo social y político. Murguía orienta la recepción estética, política y social de su mujer, extrayéndose voluntariamente del ámbito intimista de la esfera familiar, corroborando una vez más las teorías sobre la mujer de Simone de Beauvoir: los esposos nunca serán iguales. Rosalía se rebela contra la pasividad a la que la reduce su matrimonio, pero, al mismo tiempo, las fuerzas falocráticas del campo social limitan el alcance de dicha rebelión, manipulando y deformando la dimensión estética, social y política de la mujer artista, silenciando al final de su vida, su discurso, y reducindo a la mujer que fue Rosalía, a la pasividad y a la reclusión en el hogar. Las contradicciones internas entre la mujer y la intelectual sólo pueden ser dolorosas y esta subjetividad funciona coma un filtro o pantalla entre la representación del mundo exterior y la explosión de un intimismo exacerbado. Rosalía, como Mariama, son conscientes de que escribir supone asumir una función social, sea para denunciar, en el primer caso, la situación de las capas sociales más marginales de la sociedad, sea, en el segundo, para denunciar la condición de la mujer, discriminada en la esfera familiar y discriminada por el hombre cuando éste opta por la poligamia. Ambas mujeres comprenden que la intervención de la mujer intelectual en el campo social es necesaria, pero desconfían del político por estar éste dominado exclusivamente por hombres. La escritura es un poderoso instrumento que moldea y condiciona la evolución del campo social. Al presentar el mundo real en general y el mundo de las mujeres en particular, Rosalía y Mariama proporcionan modelos alternativos que contribuyen al cambio en el seno de las mentalidades, ofrecen al lector la realidad desde otro punto de vista: crítico y transgresivo, en el caso de Rosalía; liberador de la condición feminina y de la palabra para denunciar la opresión de las mujeres en Une si longue lettre: 
Les irréversibles courants de libération de la femme qui fouettent le monde ne me laissent pas indifférente. Cet ébranlement qui viole tous les domaines, révèle et illustre nos capacités.

Mon coeur est en fête chaque fois qu'une femme émerge de l'ombre. Je sais mouvant le terrain des acquis, difficile la survie des conquêtes, les contraintes sociales bousculent toujours et l'égoïsme mâle résiste.

Instruments des uns, appâts pour d'autres, respectées ou méprisées, souvent muselées, toutes les femmes ont presque le même destin que des religions ou des législations abusives ont cimenté. (Bâ, 1981, pp. 163-164)

Si algo distingue a las dos mujeres es la instrumentalización de la que fue objeto la obra rosaliana dentro de un contexto político preciso como fue el del Rexurdimento, que en definitiva encorsetó y limitó el universo literario de la escritora gallega. Posteriormente, la imaginería bienpensante haría lo posible para ocultar su carácter subversivo, manipular su imagen durante más de un siglo y crear una Rosalía llorona, santurrona y resignada. En el sistema literario español, la manipulación fue todavía mayor: se silenció y se deturpó su obra hasta convertirla en heredera de segunda categoría de Bécquer. En vida, Rosalía aspiraba a vivir de lo que escribía, no obstante, su condición de mujer y las luchas políticas de las que fue víctima Murguía, la condenaron a la pasividad y al silencio, la limitaron social y políticamente, la instrumentalizaron literariamente. No es de extrañar que este contexto la condujera al desgarro interior y a la desesperación. Rosalía no podía asumir sin más el romanticismo vigente, de ahí la busca constante a la que somete su obra hasta derivar en el realismo. La insatisfacción rosaliana del mundo existente, contrario a sus exigencias éticas, su tendencia a refugiarse en un mundo ideal, opuesto a la realidad, se concretizan en Conto Gallego (1864), una obra que inaugura en la Península el realismo social, un siglo avant la lettre.

En lo que se refiere a la literatura femenina africana, el silenciamiento por parte de las historiografías oficiales fue más que evidente, desde el momento en que se sitúan sus orígenes a finales de los años sesenta, casi una década después de la masculina. Durante varios siglos, fueron las mujeres africanas las que transmitieron a los niños todas las leyendas e historias ancestrales, cerca del fuego o durante las labores del campo. Fueron también las mujeres las que llevaron estas historias sobre amores, revoluciones, afrentas o sueños a los palacios de príncipes y reyes. Por otro lado, la literatura oral, que se transmitió gracias a griottes anónimas o cantaderas, se pierde en la noche de los tiempos. Las primeras publicaciones femeninas ven la luz a finales del siglo XIX: Ia sudafricana Olive Schreiner publica en 1883 A story of an African farm, bajo el pseudónimo masculino de Ralph Iron; en 1930, aparecen en varias publicaciones norteamericanas, los escritos de la ghaneana Gladys Casely-Hayford, y en 1966, la novela Efuru de la nigeriana Flora Nwapa (Pereyra \& Mora, 2002: 1-2). La marginalización de la fue objeto la literatura femenina africana se refleja en la dificultad que tienen las mujeres para publicar y en el escaso interés que muestran críticos y académicos. La creación, crítica y publicación de la literatura africana fue desde siempre "un negocio masculino" (Pérez Ruiz, 2008, p. 13) y las escritoras fueron y son, con frecuencia, excluidas de las antologías de la literatura africana. Pese a las dificultades y prejuicios que tienen que afrontar las escritoras desde el momento en que se considera la escritura actividad impropia del sexo femenino, la literatura femenina africana emerge tras el silencio al que estuvo sometida durante mucho 
tiempo. La mujer escritora es consciente de que, a través de la escritura, adquiere el poder de transformar y enriquecer la imagen social, endógena y exógena, de la mujer africana.

Rosalía fue incapaz de creer en el alcance de su obra (más allá del simple captatio benevolentiae tan de rigor en la época); todas la fuerzas políticas, sociales e ideológicas del campo trabajaban en su contra. También porque la lucidez, fuente de energía para Rosalía, se lo impedía. Tampoco se pudo librar a unha revuelta total que la llevaría a la negación absoluta de su persona y de su obra. Rosalía fue una escritora refractaria, preocupada por destilar y limpiar la mirada de sus lectores, lo que explica que la ideología burguesa dominante hiciera lo posible para operar como una fuerza contraria a la emergencia de la verdad. No pudiendo silenciar a la escritora en el contexto gallego, lo más sencillo fue deturpar su imagen. Al final de su vida, la desesperación llega a su culmen. Cansada de luchar y de la incomprensión de sus contemporáneos, en Rosalía operan dos fuerzas ambivalentes: por un lado, la desconfianza ante la palabra, que la conduce a quemar sus escritos, por otro lado, la creación de una obra, En las orillas del Sar, que opera como summum totalizador dirigido a las fuerzas políticas e ideológicas de la Península. La primera fuerza de destrucción surge ante la desconfianza que la autora, lúcida y desesperada, alberga en la palabra, ante la sumisión voluntaria o manipulada de sus eventuales lectores. Cuando las palabras no consiguen atrapar las sensaciones ni expresar el mundo que las rodea, el escritor acaba por oponerse a un universo carente de sentido. Quizás la escritura no pueda conducir al escritor a lo absoluto, como lo afirmaban los escritores idealistas, mas puede aportarle un sentido a su vida, clarificar y ordenar el pensamiento. Gracias a la escritura, el escritor es capaz de desdoblarse entre la naturaleza y su humana condición. La escritura es una catarsis, un desprendimiento de la educación humanista y cristiana que baña el continente europeo, un modo de descubrir la mezcla de suplicio y de delicia que encierra la existencia terrestre. La segunda fuerza consigue que Rosalía siga creyendo en la palabra, en el lenguaje literario como único medio de expresar y de compartir su desesperación, sin dejar de ser consciente, gracias a su lucidez, de que las palabras se pueden tornar ilusión. La literatura, como todas las artes (filosofía, ciencia o política), encierra una carga precisa de ilusión que puede traicionar, ensuciar, mutilar las cosas en lugar de sugerirlas o revelarlas. La literatura, como mistificación, se puede convertir en un elemento tanto o más alienante que las religiones, las utopías políticas o las filosofías idealistas. Una vez más se pone de relieve la lucidez de Rosalía, la grandeza y la superioridad de un espíritu dotado de la clarividencia necesaria para superar el romanticismo vigente, modulado por la supremacía masculina burguesa.

Mariama apuesta por la claridad, ideal clásico necesario a la persuasión. Mas, la claridad como el hermetismo, pueden ocultar la luz y la verdad. El pensamiento colonial deja sus huellas en la escritora, marcada por la instrucción de la escuela de magisterio, escuelas creadas con el fin de formar funcionarios integrados en el sistema colonial, fieles a los valores de la civilización africana: "nous sortir de l'enlisement des traditions, superstitions et moeurs; nous faire apprécier de multiples civilisations sans reniement de la nôtre" (Bâ, 1979, p. 38). Esta instrucción femenina tenía una doble finalidad, por un lado, vencer el desequilibrio intelectual en el seno de la pareja. Por otro, educar mujeres en el espírito conciliador del universo colonial y de las tradiciones africanas, para que dicho pensamiento se transmitiera más fácilmente en el núcleo 
familiar. No obstante, su influencia no fue la esperada: a estas escuelas accedían un mínimo porcentaje de mujeres, mujeres que como Mariama pertenecían a la burguesía del país. Por otra parte, las mujeres educadas en estas escuelas van a sufrir la hostilidad femenina de las generaciones anteriores y el rechazo de las élites masculinas: "premières pionnnières de la promotion de la femme africaine, nous étions peu nombreuses. Des hommes nous taxaient d'écervelées. D'autres nous désignaient comme diablesses" (Bâ, 1979, p. 36). Estos hombres deseaban que las mujeres africanas se formaran en el respeto de las tradiciones, como buenas amas de casa, no que medraran intelectualmente. En Une si longue lettre, la madre de la protagonista se opone al matrimonio de su hija por amor y la suegra de Aïssatou no tiene reparos en obligar a su hijo a casarse de nuevo con una pretendiente de origen noble. En cierta medida estas escuelas fracasaron porque las mujeres africanas se encontraron atrapadas entre dos civilizaciones, la francesa y la africana, sin una ideología propia, sin individualidad, en una sociedad mal preparada para aceptar la instrucción femenina. Mujeres que acabarán casándose con hombres educados muy lejos del ideal de la familia occidental monógama inculcado en estas escuelas. La propia Mariama vivió tres matrimonios sucesivos sin mucha fortuna, exceptuando el tercero, aunque no sin conflictos, con el intelectual y político Obèye Diop.

III. Al coger la pluma, Rosalía y Mariama, como mujeres que sufren el silencio y la opresión del mundo masculino dominante, dejan su huella en el universo de los signos, independientemente de los motivos que las inspiraron o que las guiaron y de las formas de expresión que una y otra adoptaron en su escritura. En la Galicia del siglo $X I X$, que emerge del oscurantismo literario y lingüístico de tres siglos, y en el Senegal de la época postcolonial que se aleja poco a poco de la dominación francesa, el discurso femenino, como discurso transgresivo, va dirigido contra el pensamento masculino dominante y las mujeres se convierten en agentes esenciales de la Historia, en un elemento potencialmente subversivo de la misma. La mujer gallega del siglo XIX soporta la opresión de las fuerzas falocráticas en el dominio privado de la familia y en el campo social. La mujer africana se encuentra doblemente colonizada, por sus congéneres masculinos, como esclava doméstica, y por el discurso dominante del colonizador, como sierva leal y fiel, dispuesta a propagar sus ideas: esta situación de opresión es similar a la sufrida por las mujeres europeas un siglo antes. Al ser la política dominio de lo público y de lo masculino, Rosalía y Mariama, confinadas en el espacio interior privado de la familia, tienen vetado su acceso. En el caso de Mariama, esta imposibilidad surge del exterior, por las propias fuerzas del campo político, y desde el interior en la medida en que la escritora considera que el papel social de la mujer debe limitarse al militantismo asociativo. Mariama piensa que la mujer no está preparada, desde un punto de vista ideológico, para aceptar opiniones divergentes, circunstancia que la indispone genéticamente para la política. En el caso de Rosalía, los prejuicios sociales decimonónicos y la tradición católico-eclesiástica dominante silenciaron a la mujer escritora, librepensadora, que luchó para que el pueblo gallego tuviera voz propia. 


\section{Bibliografia}

BÂ, M. (2001). Une si longue lettre, Paris : Le serpent à plumes.

CASTRO, R. DE (1996a). Prólogo de «La Hija del mar». Obra completa. Padrón: Fundación Rosalía de Castro, pp. 15-16.

http://consellodacultura.gal/mediateca/extras/ccg_pr_al9mulleres_doc_16_lahijadelmar.pdf [14/06/2021].

CASTRO, R. DE (1996b). Las literatas. Carta a Eduarda, Obra completa. Padrón: Fundación Rosalía de Castro, pp. 493-495.

http://culturagalega.gal/album/docs/doc_16_literatas.pdf [14/06/2021].

CASTRO, R. DE (1996C). "Lieders". Obra completa. Padrón: Fundación Rosalía de Castro, pp. 491-492.

http://culturagalega.gal/album/docs/doc_16_lieders.pdf [14/06/2021].

COMTE-SPONVILLE, A. (2002). Traité du désespoir et de la béatitude, Paris : PUF.

DIA, A. T. (noviembre 1979). Interview à Mariama Bâ. Amina. http://aflit.arts.uwa.edu.au/AMINABALettre.html [14/06/2021].

Garcìa Negro, M. P. (2008). Rosalía de Castro: a inauguradora da modernidade galega. Madrygal: Revista de estudios gallegos. 11, pp. 133-136. https://dialnet.unirioja.es/servlet/articulo? codigo=2712619 [14/06/2021].

KeSTELOOT, L. (2009). Historia de la literatura negroafricana (Una visión panorámica desde la francofonía), Barcelona: El Cobre Ediciones.

LOPEZ, A. (18 de julio de 1985). Lírica y etnia: encuentro con Follas Novas. Cuaderno de Cultura/La Voz de Galicia.

http://culturagalega.gal/album/docs/sobre_16_02.pdf [14/06/2021].

MiCHel, P. (2001). Lucidité, désespoir et écriture, Angers: Presses Universitaires dAngers/Société Octave Mirbeau.

NDIAYE, M. (17 de agosto de 2011). 30 ans après sa mort : Mariama Bâ renaît à travers ses écrits. Le Populaire. https://www.seneweb.com/news/Culture/30-ans-apressa-mort-mariama-ba-renait-a-travers-ses-ecrits_n_49780.html [14/06/2021].

ONDO, M. (7 de noviembre de 2009). L'écriture féminine dans le roman francophone d'Afrique noire. La Revue des Ressources.

https://www.larevuedesressources.org/l-ecriture-feminine-dans-le-romanfrancophone-d-afrique-noire, 1366.html [14/06/2021].

Pereyra, V. \& MORA, L. (1 1 de junio de 2002). Literatura femenina y feminista del África negra. El corresponsal de Medio Oriente y África.

http://www.elcorresponsal.com/modules.php?name=Stories_Archive\&sa=show _month\&year=2002\&month=06\&month_l=Junio [26/02/2015].

PÉREZ RUIZ, B. (2008). Mirar al mundo con ojos nuevos: escritoras africanas. Cuadernos de la Fundación Sur (Departamento África), 22 (3).

http://centroderecursos.alboan.org/ebooks/0000/0561/12_PER_MIR.pdf [14/06/2021].

PÉREZ RUIZ, B. (abril de 2010). Personajes femeninos en la literatura de autoras africanas frente al trauma: resistencia, adaptación y pragmatismo. Oráfrica, revista de oralidad africana, 6, pp. 171-178.

https://raco.cat/index.php/Orafrica/article/view/225170/306402 [14/06/2021].

PÉREZ RuIz, B. (2015). Otra manera de sentir: feminismos negros, género y estudios literarios en el África subsahariana. Premio Elisa Pérez Vera. Madrid: UNED. https://docplayer.es/18761769-Otra-manera-de-sentir.html [14/06/2021]. 
Poullain, G. (1976). Marina Mayoral. La poesía de Rosalía de Castro. Bulletin Hispanique, 78 (1), pp. 148-153. https://www.persee.fr/doc/hispa_00074640_1976_num_78_1_4196_t1_0148_0000_2 [14/06/2021].

TсномBA, I. N. (6 de junio de 2011 ). L'image de la femme sénégalaise dans Une si longue lettre de Mariama Bâ. Mondesfrancophones.com. Revue mondiale des francophonies.

https://mondesfrancophones.com/espaces/afriques//\%e2\%80\%99image-de-lafemme-senegalaise-dans-une-si-longue-lettre-de-mariama-ba/ [14/06/2021]. 